\title{
BOTÂNICO, MA NON SOLO: A VIAGEM DE LUIGI BUSCALIONI NA AMAZÔNIA EM 1899
}

\author{
Andrea Ciacchi ${ }^{1}$ iD
}

\begin{abstract}
Resumo: O médico e botânico italiano Luigi Buscalioni realizou, em 1899, uma viagem de pesquisa na Amazônia, na qual explorou especialmente o baixo Tocantins e o baixo Araguaia, onde contatou índios Parkatêjê e Apinajé. De volta à Itália, depois de várias e frustradas tentativas de participar da criação de um instituto internacional de pesquisas sobre a Amazônia, que o levaram a regressar duas vezes ao Brasil, escreveu uma detalhada descrição da sua viagem, incluindo elementos geográficos, naturais e antropológicos. Neste trabalho, busco reler o seu relato à luz de outros aspectos da sua trajetória científica, que seguiria até meados dos anos 50 na Itália, e verificar os nexos entre os seus escritos e o seu estatuto de "cientista" e de "estrangeiro".
\end{abstract}

Palavras-chave: Luigi Buscalioni; História da Amazônia; Literatura de Viagem; História da Ciência; Expedições Científicas.

\section{BOTANIST, MA NON SOLO: LUIGI BUSCALIONI'S TRIP TO THE AMAZON IN 1899}

\begin{abstract}
The Italian physician and botanist Luigi Buscalioni made a research trip to the Amazon in 1899, in which he mainly explored the lower Tocantins and the lower Araguaia, where he contacted the Parkatêjê and Apinajé Indigenous. Returning to Italy, after several unsuccessful attempts to participate in the creation of an international Amazon research institute, which led him to return twice to Brazil, he wrote a detailed description of his trip, including geographical, natural and anthropological elements. In this paper I seek to reread his account in the light of other aspects of his scientific trajectory, which would follow until the mid-1950s in Italy, and to check the links between his writings and his status as a "scientist" and "foreigner."
\end{abstract}

Keywords: Luigi Buscalioni; Amazon History; Travel Literature; History of Science; Scientific Expeditions.

\section{BOTANISTE, MA NON SOLO: LE VOYAGE DE LUIGI BUSCALIONI EM L'AMAZONE EN 1899}

Résumé: Le médecin et botaniste italien Luigi Buscalioni effectue un voyage de recherche en Amazonie en 1899, au cours duquel il explore principalement le Tocantins inférieur et l'Araguaia inférieur, où il contacte les Parkatêjê et les Apinajé. De retour en Italie, après plusieurs tentatives infructueuses de participer à la création d'un institut de recherche international sur l'Amazonie, ce qui l'a conduit à retourner au Brésil deux fois de plus, il a écrit et publié une description détaillée de son voyage, y compris des éléments géographiques, naturels et anthropologiques. Dans cet article, j'essaie de relire son récit à la lumière d'autres aspects de sa carrière scientifique, qui se poursuivra jusqu'au milieu des années 1950 en Italie, et de vérifier les liens entre ses écrits et son statut de "scientifique" et d' "étranger".

Mots-clés: Luigi Buscalioni; Histoire de l'Amazonie; Littérature de Voyage; Histoire de la Science; expéditions scientifiques.

\footnotetext{
1 Antropólogo pela Universidade de Roma - La Sapienza (1984), mestre em Letras pela Universidade Federal da Paraíba (1988) e doutor em Iberistica pela Universidade de Bolonha (1993), trabalha no Brasil desde 1994. É docente da Universidade Federal da Integração Latino-Americana desde 2010. Dedica-se a estudos de história dos intelectuais e do pensamento social na América Latina.
}

Revista Escritas do Tempo - v. 1, n. 3, nov/2019-fev/2020 - p. 226-246 


\section{BOTÁNICO, MA NO SOLO: EL VIAJE DE LUIGI BUSCALIONI AL AMAZONAS EN 1899}

Resumen: El médico y botánico italiano Luigi Buscalioni realizó un viaje de investigación en el Amazonas en 1899, en el que exploró principalmente los bajos Tocantins y el bajo Araguaia, donde contactó a los indios Parkatêjê y Apinajé. Al regresar a Italia, luego de varios intentos fallidos de participar en la creación de un instituto internacional de investigación amazónica, que los llevaran a regresar dos veces a Brasil, escribió una descripción detallada de su viaje, incluidos elementos geográficos, naturales y antropológicos. . En este artículo, intento releer su relato a la luz de otros aspectos de su carrera científica, que seguiría hasta mediados de la década de 1950 en Italia, y verificar los vínculos entre sus escritos y su condición de "científico" y "extranjero".

Palabras-clave: Luigi Buscalioni; Historia amazónica; Literatura de viajes; Historia de la ciencia; expediciones científicas.

\section{Introdução ${ }^{2}$}

O nome do botânico italiano Luigi Buscalioni, entre os antropólogos, é conhecido sobretudo pelas referências nada elogiosas que lhe fez Curt Nimuendaju (1939), quando o etnólogo teuto-brasileiro se dedicava ao estudo dos Apinajé. Referências mais curtas e pontuais também aparecem em alguns poucos trabalhos mais recentes sobre os "Gaviões" (Parkatêjê). ${ }^{3}$ Todos os autores referem-se a alguns trechos de Una Escursione botanica nell'Amazzonia, obra publicada em Roma, pela Società Geografica Italiana, em 1901, ${ }^{4}$ e relativa à viagem que Buscalioni fez entre março e setembro de 1899, de Belém até a região da antiga Vila de São Vicente do Araguaia, atual município de Araguatins, hoje no estado de Tocantins, percorrendo as bacias dos rios Tocantins e Araguaia. Mas quem foi Luigi Buscalioni?

Nascido em $1863^{5}$, em Turim, ou seja, na capital do recém-criado (1861) Reino da Itália, filho de um jornalista e político conservador, dedicou-se unicamente à botânica, embora também tivesse concluído o curso de medicina. Foi, aliás, na qualidade de "médico de bordo" de um navio de carga italiano, adaptado para transporte

\footnotetext{
${ }^{2}$ Este trabalho insere-se na minha pesquisa de pós-doutorado desenvolvida em 2019, na Itália, tendo por temática principal as relações intelectuais entre Itália e América do Sul entre 1850 e 1930.

${ }^{3}$ Para um resumo crítico recente sobre as várias questões (sobretudo de denominação) que envolvem os grupos jê dessa região, cf. Miranda (2015). Vale sinalizar que a recepção negativa de alguns trechos do livro de Buscalioni refere-se exclusivamente às suas observações de cunho direta ou indiretamente etnográfico.

${ }^{4} \mathrm{O}$ livro, acrescido de um texto sobre um "Progetto d'impianto di un Istituto Botanico Internazionale nell'Amazzonia", pertence à coleção de José Mindlin e está, portanto, disponível na "Biblioteca Brasiliana Guita e José Mindlin", em: https://digital.bbm.usp.br/handle/bbm/5261. Acesso em: 14 jul. 2019.

5 As fontes utilizadas para esta síntese da trajetória biográfica e acadêmica de Buscalioni são, principalmente, Daly e Millozza (2007) e Giacomini (1972), além das obras do próprio autor, referenciadas no final. Não elaborei uma crítica sistemática das fontes, embora, quando cabível, apresente as minhas observações em casos de incongruências.
} 
de emigrantes de Gênova ao Rio de Janeiro, em 1893, que teve uma primeira experiência de contato com o Brasil. Experiência extremamente negativa, ${ }^{6}$ o que não impediu, porém, que o nosso autor, agora livre docente de Botânica na Universidade de Roma, planejasse e realizasse uma missão científica na Amazônia brasileira.

Esta experiência foi relatada justamente no texto publicado em 1901 e é uma das pouquíssimas obras de Buscalioni que não tenha por assunto um tema exclusivamente botânico. Trata-se, aliás, em plena virada do século XIX para o XX, de uma prosa por vários aspectos análogas às que muitos outros viajantes, de e para vários países do mundo, escreveram para narrar, ao mesmo tempo, suas movimentações e as suas impressões, oscilando, portanto, entre a objetividade e a subjetividade. É nessa característica de "literatura de viagem" que a considero aqui, na primeira parte deste trabalho - para descrevê-la e, acima de tudo, contextualizá-la na trajetória do seu autor. Em seguida abordo, especificamente, as suas observações “etnográficas”, para verificar a sua capacidade de se inserirem no contexto mais amplo das relações intelectuais entre Europa e América Latina.

Figura 1: Retrato de Luigi Buscalioni entre 1903 e 1905

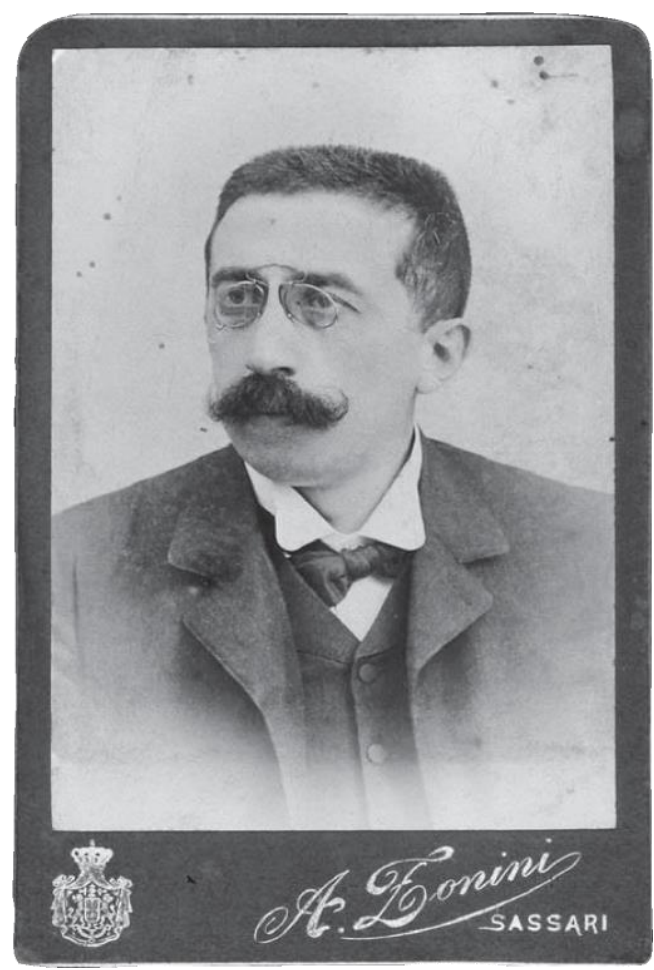

Fonte: Daly e Millozza, 2007.

\footnotetext{
${ }^{6}$ No livro La disastrosa traversata del Carlo $R$ : note di viaggio, narrou a travessia e as várias tentativas de desembarque no Rio de um grande grupo de italianos, atingidos por uma epidemia de cólera que vitimou mais de cem passageiros. O navio foi impedido de ancorar e efetuar o desembarque dos passageiros e, em seguida, expulso. Cf. Constantino (s.d.).
} 


\section{A viagem e as suas margens}

Em 1899, Buscalioni tinha trinta e seis anos, e já acumulara consistente experiência científica. Publicara numerosos trabalhos em revistas renomadas, como, sobretudo, Malpighia, fundada em 1897 na cidade siciliana de Messina, por iniciativa de Antonino Borzí, catedrático daquela universidade. Como assistente de catedráticos mais velhos, lecionara nas universidades de Turim (1891), de Parma (1892-1893), Gotinga (1896) e Roma (1897), além de ter realizado curtas viagens no Oriente médio e na Índia, sobre as quais, porém, não dispomos de informações mais detalhadas (DALY; MILLOZZA, 2007).

Se observada retrospectivamente, a sua trajetória aponta para a participação no movimento de renovação da ciência italiana (aqui, em particular, das Ciências Biológicas), que se afasta do positivismo, depois de acolher em formas diferentes as sugestões do darwinismo. Um dos aspectos dessa renovação da vida cultural e intelectual italiana, no período que vai da unificação nacional à virada do século XX (ou seja, no percurso entre o romantismo e o positivismo) é o que permitiu uma reaproximação entre a cultura italiana e a europeia, nomeadamente a francesa e a alemã, tendo como efeito colateral uma série de tentativas de "desprovincialização", incluindo investidas contra as velhas retóricas nacionalistas, os formalismos e os reacionarismos (CANDELORO, 1968).

Para além da sua passagem por uma universidade alemã, Buscalioni esteve em constante contato com colegas de outros países, e da própria colaboração com a revista Malpighia, que publicava contribuições de botânicos estrangeiros e da qual ele mesmo viria a ser um dos editores, ${ }^{7}$ essa decisão de se dedicar ao estudo de plantas exóticas é sintomática do perfil intelectual do nosso autor. No final da sua carreira acadêmica e científica, que incluiu a direção de vários jardins botânicos ligados às universidades onde lecionou, e após a sua morte (1953), o seu nome está acoplado a 206 espécies botânicas que ele descreveu e/ou identificou, de acordo com o International Plant Names Index (IPNI). ${ }^{8}$

A redação do relato da sua "excursão" brasileira foi finalizada a bordo do vapor "Rio Amazonas", que o levava de volta à Itália. O texto, publicado originariamente em quatro partes do Bollettino da Sociedade Geográfica Italiana em 1901, foi reunido em

\footnotetext{
${ }^{7}$ A coleção completa de Malpighia foi digitalizada e se encontra disponível em https://archive.org/, desde o vol. 1 (1887) até o vol. 29 (1921-1923). Acesso em: 18 jul. 2019.

${ }^{8}$ Cf. https://www.ipni.org/a/1316-1. Acesso em: 19 jul. 2019.
} 
volume, pela mesma entidade, no mesmo ano. A obra, com 140 páginas, é composta por doze capítulos: os três primeiros narram os preparativos e as etapas da viagem; os quatro sucessivos abordam, de forma mais geral, "o brasileiro sob o ponto de vista étnico e social", as populações indígenas que ele conheceu, as principais doenças registradas nas regiões visitadas, e a fauna da bacia do Tocantins. Os derradeiros cinco capítulos tratam de assuntos botânicos, geológicos e climáticos, sendo o último dedicado, de forma muito específica às plantas mirmecófilas, chegando a delinear uma "nova teoria sobre a mirmecofilia".

O contexto social e científico da Amazônia na virada dos séculos XIX e XX é determinado, como se sabe, pelo apogeu do chamado Ciclo da borracha, que esteve por trás tanto da modernização urbanística da cidade de Belém, quanto das transformações sociais e políticas em toda a região, e, finalmente, da criação do Museu Paraense, que serviu de base de apoio para a expedição de Buscalioni. O viajante observa, com propriedade:

Até poucos anos atrás, a cidade, totalmente desprovida de elegância, só apresentava um labirinto de ruazinhas não muito limpas, mal calçadas e cheias de casinhas baixas, mal construídas, escuras e às vezes também estragadas pelas intempéries. Hoje em dia, ao contrário, graças ao grande movimento comercial despertado no país pela descoberta do látex do rio Tocantins e graças à extraordinária importância da borracha, a cidade ressurgiu, pode-se dizer, a uma nova vida e se tornou um dos entrepostos comerciais mais ativos. Os casebres de madeira e os barracos foram sendo demolidos; grandes avenidas, iluminadas por luz elétrica, e alegradas por mangueiras, na sombra das quais concentra-se o melhor do Pará; praças amplas e elegantes, jardins de palmeiras, igrejas, palácios luxuosos, mansões de vários estilos arquitetônicos, grandes hospitais construídos de acordo com as regras da moderna higiene e, finalmente, bairros novos percorridos pelos bondes surgiram quase por mágica lá onde antes só existiam sujos pardieiros. O Pará, em poucos anos, mudou completamente o seu aspecto e agora pode gabar-se, com justiça, de ser um dos centros de vida brasileiros mais rebuscados (BUSCALIONI, 1901, p. 9-10). ${ }^{10}$

Buscalioni contou com apoios institucionais, políticos e financeiros relevantes: o deputado Gustavo Gavotti, armador e proprietário da empresa de navegação "Ligure

\footnotetext{
${ }^{9} \mathrm{O}$ tema do mutualismo entre algumas plantas americanas e as formigas seria também abordado por Buscalioni em artigo em colaboração com Jacques Huber, então diretor da seção botânica do Museu Paraense e, desde 1907, diretor do Museu, publicado em 1900 na revista alemã Botanisches Centralblatt: "Eine neue Theorie der Ameisenpflanzen". Além disso, Huber foi o principal apoiador e facilitador científico da viagem do italiano no Pará, em várias circunstâncias e modalidades. Sobre esse cientista suíço, cf. Sanjad (2016). Nelson Sanjad, pesquisador do próprio Museu Paraense, vem se dedicando há anos à reconstrução da trajetória de Huber, inclusive publicando os materiais coletados em http://jacqueshuberproject.blogspot.com/. Agradeço a ele pelas várias sugestões que me permitiram acessar materiais e informações relevantes para este trabalho.

${ }^{10}$ Todos os trechos das obras em italiano de Buscalioni estão reproduzidos em tradução minha.
} 
Brasiliana", em Gênova; o diretor do Instituto Botânico da Universidade de Roma, Pietro Romualdo Pirotta - nesses anos o seu superior hierárquico; o próprio Ministro da Educação, Guido Baccelli; e a Sociedade Geográfica Italiana incentivaram a viagem ${ }^{11}$, arrecadando "duas mil liras"12. Já no Pará, o cientista foi logo recebido pelo governador, José Paes de Carvalho, que lhe garantiu um "financiamento" de "15 contos" que, segundo Buscalioni, "equivalia a cerca de 13 mil liras" (Ibidem, p. 11), imensamente superior ao obtido na Itália, pois - e não seria o último. $O$ viajante teve também “como primeiro cuidado visitar o belíssimo Museu Paraense", onde teve o "raro privilégio de conhecer um ilustre botânico, o doutor Huber", que "logo se colocou à disposição da expedição e foi de validíssima serventia nas pesquisas e nas excursões botânicas que eu fiz nos arredores do Pará, no bosque municipal e alhures" (Ibidem, p. 10).

Ao longo da viagem, o visitante menciona frequentes encontros com "autoridades municipais" das pequenas cidades onde fez etapa, sempre no meio de elogios à sua gentileza e aos apoios que recebe. Nesse sentido, pode-se dizer que a viagem de Buscalioni foi caracterizada por um viés oficial que ele fez questão de declarar, inclusive com frequentes agradecimentos. Como veremos, haverá, mais adiante, o encontro com o governador do Estado de Amazonas, José Cardoso Ramalho Júnior, que também será muito significativo.

A viagem propriamente dita inicia depois que Buscalioni passou cerca de dez dias visitando a região de Castanhal nos arredores de Belém, hospedado em colônias agrícolas de imigrantes espanhóis e italianos, onde observa algumas dinâmicas da emigração para a Amazônia e, claro, coleta várias plantas. O embarque no vapor "Rio Tocantins" acontece no dia $1^{\circ}$ de maio de 1899 (erroneamente, o autor menciona $1^{\circ}$ de abril no texto). É acompanhado por Agostino Pappi, jardineiro do Regio Istituto Botanico de Roma, que já havia acumulado significativa experiência de pesquisa de campo na Eritreia (DALY; MILLOZZA, 2007, p. 3) e por um intérprete italiano,

\footnotetext{
${ }^{11}$ No texto de Buscalioni, não são detalhados os objetivos da viagem: o autor limita-se a narrar que "um dia, num bate-papo entre amigos, [...] discutia-se sobre a utilidade, para a Ciência, de uma possível viagem de exploração botânica na grande bacia do Rio Amazonas que, embora já tenha sido atravessada por muitos botânicos, constitui mesmo assim uma inesgotável fonte de estudos e pesquisas" (BUSCALIONI, 1901, p. 6).

${ }^{12}$ Mil liras foram oferecidas pelo Ministro da Educação e o mesmo valor pela Sociedade Geográfica Italiana. As passagens de ida e de volta foram custeadas pela própria empresa de navegação. O Instituto Botânico também doou alguns materiais, mas o grosso foi adquirido por Buscalioni: "papel para secagem e coleta das plantas, armas de defesa, cartuchos, grandes recipientes para guardar as plantas, instrumentos para cortar galhos elevados, frascos para o material que precisa ser conservado em álcool, etiquetas de várias formas, correias de couro, livros, câmeras e chapas fotográficas, barracas, mesinhas dobráveis, microscópios, bússolas, termômetros, roupas especiais [...] (Ibidem).
} 
concedido por Paes de Carvalho. A primeira etapa é Cametá, em seguida o vapor também fará escalas em Mocajuba, Baião e Alcobaça (atual Tucuruí).

Trata-se de um dos trechos mais amplos e, segundo Buscalioni, mais espetaculares, do rio Tocantins, aqui no seu curso inferior, a pouca distância da foz: "uma verdadeira fantasmagoria de formas vegetais que se oferecem ao olhar deslumbrado do naturalista" (BUSCALIONI, 1901, p. 16). Nesse ponto do livro, o autor relata a visita às obras da Estrada de Ferro Tocantins, lamentando o fato de que elas estão paradas e insinuando a presença de algum ilícito no desenvolvimento do projeto: 13 “O Governo [...] destinou vultuoso recurso para iniciar as obras [...], muitos projetos foram estudados, sujou-se muito papel [...], mas o dinheiro desapareceu nos bolsos dos acionistas, devorado ad usum delphini" (Ibidem, p. 17).

A viagem prossegue e o relato menciona e mistura aventuras, acontecimentos e observações: assustadores encontros com onças e jacarés, exploração de afluentes do rio Tocantins, dificuldades de navegação, com trechos a serem vencidos em canoas, atravessamento de cachoeiras, acesso a pequenas aldeias, epidemias de escarlatina e sarampo, ataques de mosquitos e, sobretudo, coletas de espécies botânicas de grande interesse para o nosso cientista.

Em seguida, Buscalioni relata, pela primeira vez, o seu encontro com uma população indígena, graças à visita que realiza à "Fazenda Bela Vista", cujo proprietário, Emanuel do Mato, teria contratado como trabalhadores agrícolas quatro índios "Gaviões", demonstrando, assim, a possibilidade de convivência pacífica dos brancos com essa etnia cuja fama, na região, seria extremamente negativa:

Uma causa que torna a região despovoada está na triste circunstância de a margem leste do rio estar quase sob o domínio dos índios Gaviões, que vivem no interior das florestas vizinhas e são temidos principalmente por seu caráter

\footnotetext{
${ }^{13} \mathrm{O}$ projeto da EFT tem como origem o decreto $\mathrm{n}^{\circ} 862$, de 16 de outubro de 1890 , em que o presidente da República, Deodoro da Fonseca, entre outras providências relativas à infraestrutura de transportes, fluviais e ferroviárias, em várias regiões do Brasil, mas especialmente na Amazônia e em Goiás, concede ao engenheiro Joaquim Rodrigues de Moraes Jardim a organização "de uma estrada de ferro, que, partindo de Patos ou de Alcobaça à margem do rio Tocantins, termine no ponto denominado Praia da Rainha ou em suas proximidades à margem do mesmo rio" e de outras linhas de navegação na mesma região". Cf. https://www2.camara.leg.br/legin/fed/decret/1824-1899/decreto-862-16-outubro-1890523759-publicacaooriginal-1-pe.html. É interessante notar que esse mesmo engenheiro militar, Joaquim Rodrigues de Morais Jardim (1836-1891), dez anos antes, publicara O Rio Araguaya. Relatório de sua Exploração, precedido de "Um Resumo histórico sobre a sua navegação", escrito pelo seu irmão, Jerônimo Rodrigues de Morais Jardim (1838-1916), também engenheiro militar, que, por sua vez, em fevereiro de 1890, pouco depois da proclamação da República, foi nomeado pelo Marechal Deodoro presidente da Comissão Geral de Viação, que se encarregaria de elaborar um plano de infraestrutura viária. Foi nesse contexto político e familiar que Joaquim recebeu a concessão para explorar a navegação nos rios Tocantins, Araguaia e outros e da mencionada ferrovia. Cf. Cachapuz (2015).
} 
selvagem. Para demonstrar quanta desconfiança esses índios inspiram, basta lembrar que os navegantes, sempre receosos de serem atacados por eles durante o sono e roubados, à noite costumam aportar suas embarcações em alguma das muitas ilhas do rio. Nós, porém, não tomamos tantas precauções e mesmo assim não vimos aparecer nenhuma horda desses habitantes da floresta, ainda pouco conhecidos e muito menos estudados (Ibidem, p. 22).

A descrição da visita à Fazenda Bela Vista (que estava situada, segundo Buscalioni, em "território" dos "Gaviões") é, de fato, muito significativa, principalmente porque relata as construções e os imaginários dos moradores brancos da região a respeito dos índios. ${ }^{14}$ Em seguida, o botânico italiano passa para a margem esquerda do Tocantins e, na "Praia da Rainha", participa de uma animada festa de São João, que descreve em tom descontraído e algo galhofeiro. ${ }^{15}$ Buscalioni e os seus companheiros estão, na realidade, no povoado de "Lago Vermelho", fundado em 1896 e que seria a origem do atual município de Itupiranga.

Nessas redondezas, o italiano conhece o "burgo agrícola" de Itacaiúnas que, como sabemos por Velho (2009), sediava, naqueles anos, uma tentativa de expansão pastoril, cujo fracasso é testemunhado e relatado por Buscalioni. Pouco depois, a partir de São João do Araguaia, a expedição entra no rio Araguaia, iniciando uma segunda etapa da viagem, que começa com dois dias de contatos com "índios Apinages", na aldeia de São Vicente - no atual município de Araguatins.

Esse curto relato ocupa uma parte do terceiro capítulo, que também narra a viagem de volta, do baixo Araguaia até Belém. Buscalioni circula entre os Apinajé num dos momentos cruciais do seu histórico de contato, no meio de uma severa queda demográfica que acompanha conflitos de terra na região. Ladeira e Azanha (2018) compilando dados de cronistas e de etnógrafos, mencionam depoimentos de 1824 (Cunha Matos, cerca de 4.200 índios), Coudreau (1894, cerca de 400 índios), Buscalioni (150) e Nimuendajú (1928, cerca de 150 indivíduos).

O viajante italiano troca cachaça por objetos ornamentais, armas, instrumentos musicais, utensílios e crânios ${ }^{16}$ e faz uma descrição sem densidade nem detalhamentos: "Demoramos dois dias na Maloca, vivendo quase a mesma vida dos Índios e morando nas suas cabanas, para podermos estudar os costumes da tribo e os caracteres

\footnotetext{
${ }^{14}$ Uma análise desse episódio, contextualizado nas relações entre "Gaviões" e não índios, está em Miranda (2015, p. 64-67).

${ }^{15}$ Essa informação permite calcular que a viagem de Buscalioni durava já quase dois meses.

${ }^{16}$ A coleção de Luigi Buscalioni conservada no Museu Pigorini em Roma compreende 87 peças, sendo 76 dos Apinajé (DORTA, 1992, p. 507).
} 
antropológicos de cada morador [...] e, o que mais importa, realizar excursões botânicas" (BUSCALIONI, 1901, p. 31, grifo meu).

A viagem de volta é muito mais rápida, pois acontece correnteza abaixo, mas a sua narração é bem mais dramática, com o autor que carrega nas tintas sobretudo na descrição dos perigos constituídos pelas numerosas cachoeiras. Buscalioni faz etapas novamente na Fazenda Bela Vista e, desta vez, consegue encontrar os índios "Gaviões" que lá moram e trabalham (estavam em viagem, quando da primeira passagem), o que ocasiona novas observações: "logo os fotografei, estudei seus caracteres e seus costumes, coletei objetos de cozinha, ornamentos e armas [...] e finalmente, registrei alguns dados linguísticos relativos às coisas mais comuns" (Ibidem, p. 34-35).

Buscalioni e Pappi estão de volta a Belém. Despedem-se do governador, que lhes oferece um almoço em companhia do cônsul da Itália e, quando estão para embarcar para a Europa no vapor "Rio Amazonas", o nosso viajante muda de ideia e resolve subir o próprio rio, até Manaus, acrescentando, assim, uma etapa imprevista e significativa à sua viagem. A descrição dessa navegação é muito sucinta, mas recheada de elogios aos "espetáculos" naturais que Buscalioni presencia, enumerando alguns dos principais acidentes geográficos que o separam de Manaus: "uma elegantíssima cidade embelezada por jardins maravilhosos, adornada por prédios soberbos, como o teatro, a Catedral, o palácio do Governador, iluminada por luz elétrica e atravessada por numerosos bondes, alguns dos quais a tração elétrica" (Ibidem, p. 40).

\section{Olhar, descrever e comentar}

Encerrada a parte narrativa do livro, do terceiro ao décimo segundo capítulo encontram-se descrições ("sociológicas", etnográficas, antropológicas, médicas, botânicas, zoológicas, geográficas e geológicas), que constituem, assim, o maior interesse da obra. Embora o autor não o declare, é evidente que o texto não tem pretensões científicas, no sentido de que - como veremos - nessas partes é menos o botânico quem fala e mais o viajante curioso. O viés das suas observações é nitidamente influenciado por aquilo que ele conheceu: o Norte do país, além dos poucos dias passados no Rio de Janeiro e em Santos por ocasião da viagem malsucedida de 1893.

A grande maioria das suas considerações origina-se da combinação de um certo senso comum "brasileiro", que pôde conhecer, observar e ouvir nas suas andanças por várias camadas sociais da região amazônica, com os seus próprios "pré-conceitos" e idiossincrasias de médico europeu, culto, inclusive com pendores filo-alemães. Desse 
ponto de vista, é sintomático notar que o único autor que ele menciona, para corroborar algumas das suas afirmações, notadamente em tema antropológico" é o agrônomo alemão Oscar Canstatt (1842-1912), que passou três anos no Brasil e, em 1871, publicou Brasilien - Land und Leute ("Brasil, terra e gente").

Sobre a composição étnica do país, por exemplo, Buscalioni afirma que:

Do ponto de vista da evolução, um cruzamento tão intenso [entre "negros", "europeus" e "indígenas"] deve ter tido uma grandíssima repercussão na formação do caráter nacional, razão pela qual alguns autores buscaram, justamente, analisar a influência moral e fisiológica exercida por essa situação. Eu tenho por mim que se o cruzamento entre raças afins entre si pode ser, às vezes, profícuo para os seus produtos, quando pelo contrário ele acontece entre raças diferentíssimas entre si, como a negra e a branca, não deve ter um êxito vantajoso, e mais ainda no caso do Brasil se o cruzamento acontece entre uma raça europeia (Portuguesa) que intelectualmente está longe de ser a mais elevada e uma outra raça (preta ou indígena), que, nesse ponto de vista pouquíssimo progredida (Ibidem, p. 42).

Além de outras observações sobre o comércio, o clima, a vida familiar, o aspecto das moradias, o italiano faz severas críticas ao clero do Brasil e, mais em geral, a aspectos da religiosidade brasileira:

Nos vilarejos perdidos no meio da floresta, ou distantes dos grandes centros, o sentimento religioso, mal compreendido pelas populações ignorantes $\mathrm{e}$ supersticiosas, torna-se frequentemente fanatismo que, explorado por algum maluco mais ou menos esperto, consegue até mesmo criar novas seitas. A história de Canudos é um exemplo realmente clássico (Ibidem, p. 50).

Ou: “quem não lembra a deletéria influência dos Jesuítas, que, para afirmar as suas pretensões políticas, mantiveram a nação num estado de verdadeira miséria intelectual e de decadência social?" (Ibidem). ${ }^{17}$

Na seção intitulada "Literatura, Artes, Ciências" (Ibidem, p. 53), Buscalioni cita cinco escritores (Macedo, Alencar, Aluísio Azevedo, Coelho Neto e Gonçalves Dias de quem transcreve e traduz a "Canção do Exílio") e um compositor, Carlos Gomes (que como sabemos, gozava de grande prestígio no campo artístico da Itália), mas nada menciona a respeito de cientistas brasileiros. ${ }^{18} \mathrm{O}$ capítulo ainda traz observações e comentários sobre o espaço doméstico, a culinária, os hábitos sociais e o vestuário da população - sempre com um certo equilíbrio entre elogios e críticas - que deixam

\footnotetext{
${ }^{17}$ Sabemos, por uma informação contida em Gandini (2004, p. 171), que houve uma troca de cartas entre Buscalioni e o conhecido historiador das religiões italiano Raffaele Pettazzoni, em 1946, em que o primeiro, entre outras considerações, se declarava um "agnóstico".

18 Ao longo do texto, porém, é mencionado várias vezes o nome do colega suíço, radicado em Belém, Jacques Huber, que, como veremos, compartilhará a autoria de alguns trabalhos com Buscalioni.
} 
transparecer, mais ou menos explicitamente, uma simpatia geral para com o país por onde havia circulado por cerca de cinco meses. $\mathrm{O}$ balanço final, de fato, é positivo:

Concluindo: o Brasileiro, como todos os povos do mundo, tem os seus defeitos e as suas virtudes: ele, porém, pode gabar-se de algumas qualidades excelentes, como uma doçura de caráter que o torna muitíssimo simpático para com o estrangeiro, uma gentileza e simplicidade de modos que servem para irmanar a todos sem distinção de graus, de profissão e de casta, e, por fim, um sentimento inato de hospitalidade quase proverbial. E isso não é pouca coisa! (Ibidem, p. $57)$.

O capítulo sucessivo é inteiramente dedicado às observações sobre os "índios" que Buscalioni conheceu na sua viagem. Oito páginas são dedicadas aos "Apinages", poucas linhas aos "Gaviões", menos ainda aos "Carayas", aos "Anambés" e a "Índios desconhecidos". Em duas oportunidades, o autor comunica que pretende, em seguida, escrever e publicar uma obra mais ampla, cujo título seria Da Roma alla Maloca degli Indios Apinages, que, porém, nunca viu a luz.

O texto, aqui, limita-se à descrição de elementos exteriores (o aspecto físico dos índios, a sua anatomia, a descrição das perfurações dos lábios e das orelhas, as pinturas corporais, as "cabanas", os utensílios de uso cotidiano, os hábitos alimentares, as festas e as danças, a sepultura dos mortos, as práticas guerreiras, e algumas duvidosíssimas anotações sobre a língua).

Nada se encontra a respeito da cosmologia, da religião ou da organização social dos Apinajé, a não ser a afirmação duramente criticada por Nimuendaju (1939, p. 78-79 e 133): 19 “A organização social é [...] muito rudimentar. Existe, sim, por exemplo, um simulacro de matrimônio, mas do ponto de vista dos seus efeitos, digamos, jurídicos, encontramos tão somente uma ridícula cerimônia destituída de qualquer importância" (BUSCALIONI, 1901, p. 60). Muito significativo, para situar o lugar epistemológico de Buscalioni, é o trecho em que ele narra a grosseira tapeação graças à qual conseguiu retirar de algumas sepulturas crânios para estudo posterior, convencendo o "chefe da tribo" que ele, por estar em contato direto com "Deus", poderia rezar para as almas dos defuntos. "Acompanhando as palavras com gestos de um endemoninhado, quase se [...] estivesse afetado por um ataque de êxtase religiosa" (Ibidem, p. 62), o viajante conseguiu quatro crânios, que enviou para o antropólogo italiano Cesare Lombroso, que teria se comprometido a comentá-los, justamente, para a obra que Buscalioni planejava

\footnotetext{
${ }^{19}$ Em particular, o etnólogo teuto-brasileiro, comentando exatamente esse trecho de Buscalioni relativos às cerimônias nupciais, liquida as observações do botânico italiano como sendo ditadas por "his customary inaccuracy" (1939, p. 79).
} 
produzir. No pouco espaço dedicado às demais etnias, não há também nada de relevante.

O capítulo encerra-se com um apelo aos "governos do Brasil", para que estabeleçam, "ao longo dos rios infestados pelos selvagens, colônias encarregadas de catequizar as várias tribos" (Ibidem, p. 68). Dessa forma, embora houvesse, anteriormente, demonstrado pouco apreço pelo clero do país, é evidente que o italiano enxerga na ação missionária um "mal menor" no intuito de retirar os índios do estado "selvagem" no qual os considera e descreve.

Os últimos seis capítulos da obra, como já foi dito, são dedicados a aspectos epidemiológicos, botânicos, zoológicos, geográficos e geológicos da região visitada. Neles, há algumas poucas referências a elementos antropológicos, especialmente quando o autor estabelece relações entre algumas doenças e aquilo que considera um quadro de condições higiênicas deficitárias (como nos casos da febre amarela e da disenteria). Frequentemente, Buscalioni narra algumas de suas intervenções terapêuticas diretas, em circunstâncias e lugares onde menciona grande escassez de médicos e medicamentos.

O mesmo ocorre quando o viajante relaciona algumas espécies de animais e de plantas a hábitos alimentares e a técnicas de caça, de pesca e de agricultura. É verdade, também, que os capítulos de tema botânico parecem mais fundamentados e, em particular, as informações apresentadas, embora em uma linguagem simples que deveria atingir leitores não especialistas, são distribuídas de forma mais sistemática e sempre que necessário relacionadas aos aspectos climáticos e geológicos da região. De fato, a partir da sua volta para a Itália, Buscalioni irá estabelecer uma carreira sólida, com passagens por algumas das mais reconhecidas universidades do país, e um número muito significativo de publicações, muitas das quais determinaram a ligação do seu sobrenome à nomenclatura botânica internacional. ${ }^{20}$

Nunca mais voltou a escrever sobre temas que extrapolassem a dimensão botânica, muito menos sobre temáticas "etnográficas", apesar do mencionado projeto de uma obra mais alentada sobre a sua viagem ao Brasil. Essa "separação" do país que, entretanto, tanto elogiou no seu texto de 1901, acabou, porém, provocando uma forte

\footnotetext{
${ }^{20}$ Giacomini (1972) enumera as universidades italianas onde Buscalioni ficaria lotado depois do seu regresso do Brasil: Pavia (1900), Sassari (1902), Catania (1906), Palermo (1923) e Bolonha (1928), onde se aposentaria.
} 
desilusão, relativa ao fracasso na tentativa de ajudar a criar um "Instituto Botânico Internacional", a ser sediado em Manaus ou Belém.

A história desse empreendimento está narrada, sumariamente, no texto da Escursione botanica, e, com muitos mais detalhes, num texto mais longo, publicado em 1902 no Nuovo Giornale Botanico Italiano $^{21}$ e, também, anexado no exemplar da edição de 1901 da referida Escursione conservado na Biblioteca Mindlin em São Paulo. Em síntese, Buscalioni narra que, na sua passagem por Manaus, pouco antes de embarcar para a Itália, propôs aos governadores do Amazonas, Ramalho Júnior, e, sucessivamente, em Belém, do Pará, Paes de Carvalho, a criação de um Instituto Botânico Internacional.

Os dois políticos brasileiros endossaram a proposta e encarregaram o italiano de verificar e coletar, na Europa, apoios científicos, políticos e econômicos, inclusive destinando-lhe um recurso que foi avaliado em dez mil liras. Depois de arregimentar os primeiros apoios institucionais em Roma, Buscalioni partiu para um longo tour nas principais cidades europeias e, no texto, descreve em detalhes as várias reações, de docentes, pesquisadores, diretores de museus, institutos e jardins botânicos, mas, também, de autoridades políticas e membros de famílias reais.

O circuito incluiu etapas em onze países: Áustria, Rússia, Alemanha (onde visitou seis cidades), Suíça (quatro cidades), França, Inglaterra, Bélgica, Holanda, Dinamarca, Suécia e Noruega. De volta a Roma, em lugar das esperadas cartas dos dois governadores brasileiros, que ele ia informando paulatinamente dos avanços das conversações europeias, Buscalioni surpreendeu-se com uma correspondência do seu colega, o dr. Huber, diretor botânico do Museu Paraense, que jogava um balde de água fria nas suas pretensões:

deixava-me compreender que não pretendia mais colaborar com o meu projeto e que as condições políticas e financeiras, pouco flóridas, do Pará e do Amazonas, não permitiriam mais a esses Estados o luxo da fundação de um Instituto tão grandioso, a propósito do qual também seria difícil estabelecer um acordo completo entre o Pará e o Amazonas e conciliar os opostos interesses desses dois Estados com relação à questão da sua sede (BUSCALIONI, 1902, p. 2223).

\footnotetext{
${ }^{21}$ Periódico que era o órgão oficial da "Società Botanica Italiana". O fascículo 1 do volume 9 (janeiro de 1902), contendo o Relatório de Buscalioni - "Il Progetto d'Impianto di un Istituto Botanico Internazionale nell'Amazzonia" está também disponível em: https://bibdigital.rjb.csic.es/medias/d2/d0/e9/52/d2d0e9529851-4464-a501-ca4d3468c387/files/P0036_S2_09.pdf. Acesso em: 01 ago. 2019.
} 
Num ímpeto, Buscalioni resolve voltar logo para o Brasil, embarcando no dia 20 de março de 1900 para Belém. Nas etapas do navio em Marselha e em Lisboa, ainda aproveita para mais encontros com autoridades francesas e portuguesas para angariar mais apoios. Segundo o relato do nosso autor, em Belém o governador confirma o seu apoio, prometendo, aliás, solicitar oficialmente à Assembleia Legislativa do Pará o vultuoso recurso necessário. Mas, será no encontro com Huber, no Museu Goeldi, que Buscalioni compreende o que de fato estava ocorrendo. A oposição ao seu projeto viria do próprio Emilio Goeldi, preocupado "que um estrangeiro viesse propor a fundação de um Instituto que, na sua opinião, teria fortíssima afinidade com o atual Museu Paraense e como tal prejudicaria o mesmo ou poderia provocar radicais modificações na sua organização" (Ibidem, p. 24).

Depois de conversar em Manaus com Ramalho Júnior, que também reitera o seu apoio e promete a liberação de recursos, Buscalioni volta a Belém, onde o governador sugere que se dirija à Suíça, para conversar pessoalmente com o dr. Goeldi, que se encontrava em Zurich. Quando os dois botânicos finalmente estão vis-à-vis, chegam, aparentemente, a um consenso e redigem uma espécie de protocolo de intenções que garantiria, ao mesmo tempo, a criação do novo Instituto e a autonomia do Museu Paraense, além de prever a criação de uma seção da nova instituição em Manaus, além de muitos outros detalhes de natureza organizacional e administrativa (BUSCALIONI, 1902, p. 26-28).

Entretanto, uma carta enviada em maio de 1901 para Paes de Carvalho, com o relato circunstanciado dos acordos estabelecidos entre Goeldi e Buscalioni, nunca teve resposta, segundo o nosso autor. Assim, ele se dispõe a enfrentar uma terceira viagem à Amazônia, em novembro. Em Belém, uma nova decepção: o governador do Pará diz-lhe que, estando no fim do seu mandato, não tem mais interesse em dar continuidade ao projeto e acrescenta que Goeldi lhe escrevera com um parecer desfavorável - o que, evidentemente, causa grande espanto no cientista, que logo escreve ao colega suíço solicitando explicações, também ficando sem resposta. Em Manaus, então, ele tenta, sem sucesso, ser recebido pelo novo governador do Amazonas, Silvério Nery. Encerrase, assim, melancolicamente, o sonho amazônico de Luigi Buscalioni. ${ }^{22}$ Poucas semanas depois do seu regresso definitivo à Itália, ele seria aprovado no concurso para a Cátedra

${ }^{22}$ Daly e Millozza (2007) sustentam que o projeto fracassado seria um embrião daquilo que, muito mais tarde (1952), viria a ser, em Manaus, o Instituto Nacional de Pesquisas Amazônicas (INPA).

Revista Escritas do Tempo - v. 1, n. 3, nov/2019-fev/2020 - p. 226-246 
de Botânica da Universidade de Sassari, dando início, assim, à fase mais institucional da sua carreira acadêmica.

Muito mais tarde, dez anos depois da sua aposentadoria e da conclusão da sua trajetória acadêmica, o velho professor voltaria a comentar as suas viagens de exploração (BUSCALIONI, 1945 e 1949), acrescentando detalhes e "corrigindo" outros. ${ }^{23}$ Essa produção conclusiva do autor parece abrandar as agruras ocasionadas pelo fracasso do projeto internacional, mas, ao mesmo tempo, configura-se como um vigoroso ajuste de contas com o mundo acadêmico italiano, acusado, sem meias palavras, de ter tentado (conseguindo às vezes) estorvar a sua carreira científica.

As disputas teriam se originado justamente a partir e por causa da rica coleção de espécimes e amostras botânicas da Amazônia que Buscalioni levara para a Itália. O seu antigo chefe no Instituto Botânico de Roma, o prof. Pirotta, impediu que ele continuasse tendo acesso às plantas, alegando que Buscalioni já não pertencia mais aos quadros do Instituto. ${ }^{24} \mathrm{~A}$ briga durou anos a fio, envolveu indiretamente Huber e passou por várias instâncias judiciais. ${ }^{25}$ No mesmo texto, Buscalioni (1945, p. 76-81) dá conta de outras facetas da sua colaboração com Jacques Huber, sobretudo em questões que, nas fronteiras entre botânica, geologia, limnologia e geografia física, envolvem algumas peculiares formações de "savanas fluviais", que o italiano reivindica como uma relevante contribuição dele mesmo e do seu colega suíço. Finalmente, Buscalioni ilustra com detalhes o que ele considera a sua "descoberta": a presença, em regiões limítrofes às várzeas do alto Tocantins, da Castilla elástica, outra espécie capaz de produzir látex para borracha, antes reconhecida apenas no México, na América Central, na Colômbia e no Ecuador, e o que ele denuncia serem tentativas de desqualifica-lo como autor do achado. $^{26}$

\footnotetext{
${ }^{23}$ As discrepâncias entre Buscalioni (1901) e Buscalioni (1945) referem-se, especificamente, às suas relações com o governador do Pará, no tocante a alguns incentivos financeiros oferecidos por ele e a um pedido específico de informações sobre uma espécie botânica produtora de látex capaz de ser transformado em borracha (Castilla elastica). Huber (1902) parece confirmar que esse pedido veio dele, Huber, e não do governador. Devo à gentileza de Maurizio Avanzolini, da Biblioteca do Arquiginásio de Bolonha, o acesso aos textos de Buscalioni de 1945 e 1949.

${ }^{24}$ Ele, de fato, havia se desligado do IB por ocasião das suas viagens relacionadas à criação do Instituto internacional.

${ }^{25}$ Sobre essa disputa e, mais em geral, sobre as vicissitudes da coleção de Buscalioni, cf. Daly \& Millozza (2007).

${ }^{26}$ A animosidade de Buscalioni para com os seus detratores parece chegar ao ponto mais alto quando ele, no final desse mesmo texto $(1945$, p. 81 ), afirma ter assistido ao filme "Il tesoro del tropico" (na realidade, em italiano, Il tesoro dei tropici, ou seja, Kautschuk, longa-metragem de ficção dirigido pelo diretor suíço Eduard von Borsody em 1938, e conhecido também como The Green Hell e, em português, O Inferno verde). Trata-se, na realidade, de um filme de propaganda nazista, em que é ficcionalizada a tentativa inglesa de quebra do monopólio brasileiro da borracha natural. Para tanto, a produção misturou
} 


\section{O especialista e o amador}

A relevância da trajetória de Buscalioni no campo científico da botânica, iniciada pouco antes da sua primeira viagem à Amazônia, consolidada graças a essa excursão, e confirmada pela sua carreira acadêmica sucessiva, é algo já incorporado à história italiana e internacional dessa disciplina. ${ }^{27}$ Entretanto, como em muitos outros casos de cientistas naturais que se aventuraram em territórios extraeuropeus, nesse empreendimento brasileiro aparece a faceta "amadora" de alguém que se compromete a também dissertar (narrativa, descritiva e "cientificamente") sobre outros aspectos da realidade que ele enfrenta, em particular a "antropológica".

Já foi destacado, aqui, que na sua grande maioria as observações etnográficas de Buscalioni são superficiais, devedoras, ao mesmo tempo, de um certo senso comum local (alimentado por e retroalimentando preconceitos raciais, étnicos e sociais gerais no Brasil e específicos no Norte do país) e, também, de observações e juízos de outros viajantes europeus, cujas obras Buscalioni lera antes e durante a viagem. ${ }^{28}$

cenas documentais com gravações em estúdio (ROCHA FILHO, 2010). Mas Buscalioni afirma: "é evidente que o tema [do filme] foi tirado da minha publicação supramencionada [...] da qual eu havia doado algumas cópias ao Museu Paraense, onde, provavelmente, a produção do filme teve oportunidade de consultá-la. Não é necessário acrescentar que nas sequências da fita havia bem pouca verdade, mas faço questão de ressaltar que o protagonista da descoberta tinha um sobrenome alemão, e que o nome do governador do Pará, promotor da expedição, também foi falsificado. Será que é lícita tamanha deformação da verdade, que poderia induzir algum botânico a achar que eu publiquei mentiras? Afinal, o cinema é um meio de divulgação científica que deveria mencionar os nomes dos autores a que se inspira nas suas realizações" (BUSCALIONI, 1945, p. 81). É necessário informar que eu não tive acesso ao filme e, portanto, não pude verificar diretamente a causa desse ressentimento de Buscalioni. Numa análise bastante aprofundada do filme, Rocha Filho (Ibidem) destaca a presença de cenas "documentais" intercaladas às de "ficção", sendo possível, portanto, que tal menção, acusada por Buscalioni, esteja de fato presente na fita.

${ }^{27}$ Mas, aparentemente, não aos estudos brasileiros. Vale mencionar, porém, a referência a Buscalioni presente num trabalho de um dos mais importantes geógrafos brasileiros (AB'SABER, 2012, p. 21). Ao apresentar o que ele define "estudos de etno-ciências aplicados à Amazônia brasileira", subdividindo-os em etapas cronológicas, o autor menciona Buscalioni no mesmo grupo no qual insere "Bates, Walace, Henri, Olga Coudreau, Chermon de Miranda, Barbosa Rodrigues, João Alberto Maso, Stradelli, [...] e, sobretudo, Richard Spruce", sem, entretanto, fazer comentários para eles.

${ }^{28} \mathrm{Um}$ estudo das obras de assunto brasileiro presentes na biblioteca pessoal de Buscalioni e hoje conservadas na Biblioteca do Dipartimento di Scienze Biologiche Geologiche e Ambientali da Universidade de Bolonha - que, como vimos, foi a instituição onde ele encerrou a sua carreira, permitiria aprofundar esse viés de pesquisa. Numa primeira, rápida e provisória investida, que se tornou possível graças à inestimável colaboração da doutora Claudia Bonfiglioli, bibliotecária desse Departamento, a quem vai o meu mais caloroso agradecimento, foi possível levantar vários títulos que pertenceram a Berlusconi e que foram por ele anotados à margem. Entre eles, Journey in Brazil, de Louis Agassiz (ed. de 1868); o vol. II do Diccionario das Plantas Úteis do Brasil e das Exóticas Cultivadas, de Manuel Pio Corrêa (na ed. de 1932, com dedicatória do autor); a Enumeratio Palmarum Novarum de J. Barbosa Rodrigues (na ed. de 1879); Unter den naturvölkern Zentral-Brasiliens: Reiseschilderung und ergebnisse der zweiten Schingú-expedition, 1887-1888, de Karl von den Steinen (ed. de 1897); o Atlas zur Beschreibung der Reise in Brasilien, de Spix e Martius (sem indicação de data); Kupfer und Karten zum Item Band der Reise nach Brasilien in den Jahren 1815 bis 1817, de Maximilian Wied-Neuwied (ed. de 1821).

Revista Escritas do Tempo - v. 1, n. 3, nov/2019-fev/2020 - p. 226-246 
Aqui, agora, pretendo, porém, destacar um elemento que permite compreender a articulação entre o especialista (o botânico) e o amador (o "etnógrafo"), no relato de Buscalioni: a menção, ainda que pouco frequente, a aspectos que hoje consideraríamos de etno-botânica. No IX capítulo da sua obra ("Principali piante coltivate od utili del Para"), Buscalioni introduz umas poucas informações a usos locais de algumas espécies. A identificação dos sujeitos dessas práticas está consignada em expressões vagas, mas que se afunilam: "o homem", "as populações da América", "os brasileiros", "o indígena", "os índios". Um parágrafo, em especial, chama a atenção:

Da imensidão das florestas americanas a atividade do homem soube obter um número realmente imenso de essências utilíssimas seja pela natureza da sua madeira, seja pelas substâncias de diferente constituição química que elas contêm, seja pelos produtos medicamentosos que elas vão elaborando na casca, nas folhas e em outras partes, e seja, finalmente, porque alguns dos seus órgãos ou membros constituem um alimento precioso para o homem. Nesta mais que secular busca de plantas úteis, a que ainda hoje se dedica o homem, o indígena, com aquele olhar agudíssimo e com aquela espécie de tato quase instintivo que é uma das suas características, soube muito frequentemente ser um guia para o Europeu, na descoberta de determinados produtos que somente mais tarde a química conseguiu evidenciar no estado mais ou menos puro (BUSCALIONI, 1901, p. 104-105, grifo meu).

Pouco adiante, o autor menciona o uso que os indígenas fazem de algumas madeiras ("pau-ferro", jacarandá, cedrela, entre outras), sendo que "de algumas delas os índios conseguem obter canoas já quase prontas e de grande tamanho, destacando-lhe a casca, com uma técnica bastante primitiva, baseada na ação do fogo" (BUSCALIONI, 1901, p. 105). Finalmente, entre as espécies capazes de fornecer alimentos, Buscalioni menciona o "mais", que o autor informa ser "uma planta cultivada com especial predileção por algumas tribos de índios (Gaviões), os quais, aliás, souberam obter algumas variedades caracterizadas pela diversidade de coloração das sementes" (BUSCALIONI, 1901, p. 112). Diferentemente do que acontece com quase todas as outras informações botânicas, aqui o viajante não informa o nome científico da planta que ele denomina "mais" [milho], sendo assim, permanece uma dúvida de identificação, reforçada pela última frase do mesmo parágrafo: “Os frutos, porém, são utilizados quase exclusivamente como ração para os cavalos, mulas e bois" (Ibidem).

No restante do capítulo, o âmbito de referência dos usos humanos dos recursos naturais (assim como, porém, mais raramente, em outros capítulos da mesma obra) é sempre o mais geral: “os brasileiros”, ou até mesmo "o homem”. Sem exceções, sempre 
que esses saberes e/ou práticas parecem se chocar com os conhecimentos científicos de que o próprio Buscalioni se faz portador, os primeiros são confrontados aos segundos, sendo assim criticados, rebaixados ou menosprezados.

Numa outra dimensão, porém simétrica a esta, aparece em mais de uma oportunidade (nos casos, por exemplo, dos antídotos e das práticas de combate aos venenos das serpentes peçonhentas, e, numa perspectiva que engloba aspectos de racionalidade econômica aliada a saberes científicos específicos, dos conhecimentos sobre as espécies capazes de fornecer matéria-prima para a produção da borracha), o confronto entre os conhecimentos científicos brasileiros e os conhecimentos científicos europeus, dos quais o próprio Buscalioni se apresenta, evidentemente, como um representante - sempre com desvantagem para os primeiros. Assim, ao lado de vários especialistas europeus mencionados pelo viajante, só um representante da ciência brasileira institucionalizada parece conseguir ficar em pé de igualdade: o botânico suíço Jacques Huber, lotado no Museu Paraense, e coautor de alguns trabalhos assinados por ele e Buscalioni!

Dessa forma, parece-me que o "amadorismo" etno-antropológico de Luigi Buscalioni possui uma analogia estrutural com a rudimentariedade das práticas e dos saberes locais, principalmente (mas não só) quando populares ou fincados na alteridade, se e quando o observamos com a lente "científica" do conhecimento antropológico contemporâneo. Mesmo assim, a dimensão etnográfica do relato de Buscalioni não pode ser omitida, ou liquidada. Se ela nos diz pouco ou mesmo quase nada sobre aspectos da vida indígena naquelas regiões, naquele quadrante histórico, mesmo assim adiciona um elemento relevante na compreensão de algumas dinâmicas intelectuais na virada dos séculos XIX e XX, e acrescenta motivos de reflexão para uma discussão que, além de historiográfica também pode ser metodológica.

Em outras palavras, o tom e a organização (narrativa e descritiva) das observações científicas (ou seja, de um cientista natural, "amador" de ciências humanas) de um italiano na Amazônia conferem novas inflexões ao que consideramos, no decurso cronológico de cento e vinte anos que nos separam da viagem de Buscalioni, "moderno" e/ou colonial.

Seria possível, então, formular uma pergunta: a distância e o contraste entre o cientista e o amador são engendrados na "ciência" ou na "nacionalidade"? O que é mais relevante, aqui: Buscalioni ser um botânico ou ser um italiano? As possíveis perguntas (muito antes de ensejarem respostas) apontam para uma indagação sobre o lugar de 
produção da literatura sobre a alteridade: a ciência ou a história (aqui entendida como o conjunto de determinações que permitem a um europeu enxergar o mundo a partir de um ponto de vista localizado, justamente, na Europa)?

Parece-me que a lógica desse sistema de perguntas aponta para um âmbito que extrapola as relações entre ciências "naturais" e ciências "humanas", pois poderia se situar com muita propriedade na própria história da etnografia (inclusive oitocentista). Minha hipótese é que o rebaixamento a que é submetida a experiência social indígena (e a amazônica, e a brasileira), por Buscalioni, constitui um mecanismo de dupla complexidade, buscando e mobilizando elementos (apresentados, não por acaso, como conhecimentos) que se beneficiam, ideologicamente, da aparência do seu berço científico, para ocultar a sua determinação real, que é étnica e histórica.

Esta, por sua vez, não se esgota na produção das lógicas dos campos científicos, pois compreende, a rigor, todos os lugares de produção de ideias, de falas e de representações - inclusive os antropológicos. À margem dessas considerações, portanto, insiro uma sugestão para desenvolvimentos futuros, vislumbrando uma reflexão sobre o estatuto dos estudos sobre literatura de viagem nas suas interfaces (epistemológicas, antes que metodológicas) com a história da(s) ciência(s). Sempre que um viajante europeu, independentemente da sua colocação oficial num ou outro campo científico, produzir um relato sobre algum aspecto que ele mesmo reconheça como "extraeuropeu" instaurará também um lugar científico de fala? E um lugar, por isso, moderno e/ou colonial? Minha leitura do livro de Buscalioni me inclina a uma resposta afirmativa, mas não tenho como exagerar, por enquanto, o alcance dessa primeira observação, que careceria de amostras mais numerosas e oriundas de vários campos e nacionalidades.

\section{Referências}

AB'SABER, Aziz N. "Bases para o estudo dos ecossistemas da Amazônia brasileira". Estudos Avançados, São Paulo, v. 16, n. 45, 2002, p. 7-30.

BUSCALIONI, Luigi. Una escursione botanica nell'Amazzonia. Roma, Società Geografica Italiana, 1901.

"Il Progetto d'impianto di un Istituto Botanico Internazionale nell'Amazzonia". Nuovo Giornale botanico italiano (Nuova serie), Vol. IX, n. 1, Janeiro de 1902 (p. 532). Disponível em: https://bibdigital.rjb.csic.es/medias/d2/d0/e9/52/d2d0e952-98514464-a501-ca4d3468c387/files/P0036_S2_09.pdf. Acesso em: 01 ago. 2019. 
BUSCALIONI, Luigi. Le principali formazioni vegetali dei tropici e le vicence delle mie esplorazioni scientifiche attorno al mondo. Bologna, Coop. Tipografica Azzoguidi, 1945.

. Amenità universitarie ed accademiche. Bologna, Tipografia S.A.B, 1949.

CANDELORO, Giorgio. Storia dell'Italia Moderna. Vol. V. La costruzione dello Stato unitario (1860-1871), Milano, Feltrinelli, 1968.

CACHAPUZ, Paulo Brandi. "Jardim, Jerônimo de Morais" in: Dicionário da Elite Política Republicana (1889-1930), Rio de Janeiro: Fundação Getúlio Vargas, 2015. Disponível em https://cpdoc.fgv.br/sites/default/files/verbetes/primeirarepublica/JARDIM,\%20Jer\%C3\%B4nimo\%20de\%20Morais.pdf. Acesso em: 29 jul. 2019.

CONSTANTINO, Nuncia Maria Santoro de. "Cientifismo no debate sobre a emigração para o Brasil: relatos de escritores italianos". Archivio Storico dell'Emigrazione Italiana, s.l., s.d. Disponível em: https://www.asei.eu/it/2015/05/cientifismo-no-debatesobre-a-emigracao-para-o-brasil-relatos-de-escritores-italianos/. Acesso em: 24 set. 2019.

DALY, Douglas C.; MILLOZZA, Anna. "'Lost' plant collections from the Amazon 1: the 1899 expedition of Dr. Luigi Buscalioni”. Taxon, New York, vol. 56, n. 1, 2007, p. 185-199.

DORTA, Sonia Ferraro. Coleções Etnográficas (1650-1955). In: CUNHA, Manuela Carneiro da (org.). História dos índios no Brasil. São Paulo, Companhia das Letras, Secretaria Municipal de Cultura, FAPESP, 1992, p. 501-522.

GANDINI, Mario. "Raffaele Pettazzoni dall'estate 1943 alla primavera 1946". Strada maestra, n. 57, 2004, p. 21-199.

GIACOMINI, Valerio. "Buscalioni, Luigi”. In: Dizionario Biografico degli Italiani, vol. 15, 1972, on-line. Disponível em: http://www.treccani.it/enciclopedia/luigibuscalioni_(Dizionario-Biografico). Acesso em: 20 jul. 2019.

HUBER, Jacques. "Apontamentos sobre o caucho amazônico". Boletim do Museu Paraense de Historia Natural e Ethnographia (Museu Goeldi), Belém, vol. 3, n. 1/4), 1902 (p. 72-87). Disponível em: https://repositorio.museugoeldi.br/handle/mgoeldi/1141. Acesso em: 05 set. 2019.

JARDIM, Joaquim R. de Moraes. O Rio Araguaya. Relatório de sua Exloração. Rio de Janeiro, Typographia Nacional, 1880 . Disponível em: http://etnolinguistica.wdfiles.com/local--files/biblio\%3Ajardim-1880rio/O_Rio_Araguaya.pdf. Acesso em: 29 jul. 2019.

LADEIRA, Maria Elisa; AZANHA, Gilberto. "Verbete Apinajé”, 2018. Disponível em: https://pib.socioambiental.org/pt/Povo:Apinaj\%C3\%A9. Acesso em: 24 set. 2019. 
MIRANDA, Adenilson Barcelos de. Os "Gaviões da mata": uma história de resistência timbira ao Estado. Dissertação (mestrado). Goiânia, Pontifícia Universidade Católica de Goiás, Programa de Pós-Graduação em História, 2015.

NIMUENDAJU, Curt. The Apinayé. Washington, The Catholic University of America Press, 1939.

ROCHA FILHO, José. "O Terceiro Reich e as conexões culturais com o Brasil em Kautschuk". Iberoamericana, vol. X, n. 37, 2010 (p. 7-17). Disponível em: https://journals.iai.spk-berlin.de/index.php/iberoamericana/article/download/717/400. Acesso em: 05 set. 2019.

SANJAD, Nelson. "De Basileia a Belém: a carreira transnacional do botânico Jacques Huber (1867-1914)". In: CAVALCANTE, Maria Juraci Maia et alii. (rrgs.). Histórias da Pedagogia, Ciência e Religião: discursos e correntes de cá e do além-mar. Fortaleza, Edições UFC, 2016, p. 159-181.

VELHO, Otávio Guilherme. "A frente pastoril". In: Frente de expansão e estrutura agrária: estudo do processo de penetração numa área da Transamazônia [online]. Rio de Janeiro, Centro Edelstein de Pesquisas Sociais, 2009 (p. 17-28). Disponível em: http://books.scielo.org/id/zjf4z/pdf/velho-9788599662915-05.pdf. Acesso em: 30 jul. 2019. 